\title{
Level of Service Analysis Based on Maximum Number of Passengers in Waiting Room of Railway Passenger Station Using Arena Simulation
}

\author{
Bo Yang, ${ }^{1}$ Xuedong Yan, ${ }^{1}$ and Dahai Guo ${ }^{2}$ \\ ${ }^{1}$ State Key Laboratory of Rail Traffic Control and Safety, Beijing Jiaotong University, Beijing 100044, China \\ ${ }^{2}$ U.A. Whitaker College of Engineering, Florida Gulf Coast University, 10501 FGCU Boulevard South, Fort Myers, FL 33965-6565, USA \\ Correspondence should be addressed to Xuedong Yan; xdyan@bjtu.edu.cn
}

Received 11 May 2015; Revised 25 July 2015; Accepted 27 July 2015

Academic Editor: Filippo Cacace

Copyright (C) 2015 Bo Yang et al. This is an open access article distributed under the Creative Commons Attribution License, which permits unrestricted use, distribution, and reproduction in any medium, provided the original work is properly cited.

\begin{abstract}
The level of service is an important aspect of the operation and management at a railway passenger station. Particularly, the level of service in waiting room (LOSWR) is one of the most important influential factors in deciding passengers' satisfaction. This paper proposes a model for finding the LOSWR based on the maximum number of passengers, and an Arena simulation model that simulates passengers' aggregation behaviors in the waiting room is presented for analyzing the LOSWR. Through the simulation, we demonstrate how the passenger advanced arrival time and the accompany rate influence the maximum number of passengers and the LOSWR. In addition, the simulation also illustrates the effect utilities and the priority of different measures that can be used to improve the LOSWR. In detail, the simulation results demonstrate that the passenger advanced arrival time and advanced checkout time have much stronger effect utilities on the maximum number of passengers and the LOSWR than other discussed factors. The simulation suggests that the Arena is an effective simulation platform for analyzing complex passengers-related behaviors at railway passenger station.
\end{abstract}

\section{Introduction}

Railway passenger transport faces a great competition from the rapid development of other modes of transportation; it is imperative to improve its quality of services. Improving the level of service at railway passenger station is the most effective way to enhance the competitiveness of railway passenger transport [1-3]. The level of service at railway passenger station can be divided into the following parts based on the service process, including the level of service in security check, buying or picking up the tickets, waiting room and passengers' departure, and so forth.

Among the above service steps, the waiting room is the most important link to ensure the passengers' arrival and departure smoothly. It can be characterized by its maximum number of passengers and maximum residence time for passengers [4-6]. Passengers' satisfaction is significantly decided by their experience in the waiting room. Particularly, unusual rules of passengers' aggregation in waiting room could arise due to occasions, such as morning and evening rush hours, holidays, and festivals which will lead to the crowded passenger flow and bring a series of difficulties to the station's operation and management. Based on the above characteristics, a further analysis of the level of service in waiting room (LOSWR) based on passengers' satisfaction is needed and useful for both the passengers and operators.

Some studies have been conducted to evaluate the LOSWR based on passengers' satisfaction. For example, a system based on passengers' satisfaction in the waiting room is established by adopting Back Propagation (BP) neural network algorithm and a three-tier model and verified by comparing it with a fuzzy comprehensive evaluation method [7]. Thus, the level of service in waiting room can be derived. To find the relationship between the global customer satisfaction and quality of services in the waiting room, a structural equation model is formulated [8]. The main 
findings are that the service characteristics like the area of waiting room, cleanliness, and comfort level in waiting room will have positive impacts on passengers' satisfaction.

Since much information in the waiting room is unascertained during the process of level of service evaluation, unascertained measure theory could be applied in the general passengers' satisfaction. Based on establishing the evaluation index system, $\mathrm{Wu}$ and $\mathrm{Ma}$ [9] apply the information entropy theory to calculate the weight of each indicator, establishing the levels of service and the set of significant factors to determine the LOSWR. The function of Wu and Ma's study is to identify the key factors in improving the LOSWR. The maximum number of passengers in waiting room contributes to the per capita waiting area and walking environment. The study in [10], through setting the maximum number of passengers as target function in sensitivity analyses, finds that the maximum number of passengers in the waiting room is influenced by various factors, such as the passenger advanced arrival time. The study shows that the passenger advanced arrival time has a significant effect on both the maximum number of passengers and average waiting time in waiting room, thus indirectly influences the LOSWR.

However, a number of limitations exist in the previous work about the LOSWR based on passengers' satisfaction. On one hand, previous studies mainly emphasize on the evaluation of existing service facilities and seeking for remedial measures to improve the level of service. A dynamically and real-timely monitoring and controlling method is unavailable which allows the operators to take real-time or even preventive measures to maintain the LOSWR at a higher grade. On the other hand, the influential factors of the LOSWR have not been well discussed. More importantly, for the different measures that can be used to improve the LOSWR, their effect utilities and priority are unavailable currently for the operators' reference when the LOSWR needs to be improved.

In this study, the purpose of this work is to provide an evaluation model for estimating the LOSWR based on passengers' satisfaction with the method of simulating the operation process from passengers' arrival to departure at a railway passenger station. For this purpose, Fruin evaluation method [11] is adopted to measure the indicators of per capita waiting area, walking environment, and so forth, which can be used in evaluating the LOSWR. The idea behind using this method is to provide the number of passengers in each unit area based on the maximum number of passengers in the waiting room, which comes from the probability method $[12-14]$ and its successful use in the traffic engineering field $[15,16]$. In this work, the operation process from passengers' arrival to departure at a railway passenger station is conducted by adopting the Arena simulation methodology that is widely used in industrial applications. The purpose of simulation is to mimic passengers' moving process, including the behaviors of arrival, waiting, and departure, and output the maximum number of passengers in the waiting room which could allow us to evaluate the LOSWR real-timely and dynamically.

Finally a proof of reliability of the proposed models is carried out through the use of the Arena simulation methodology to analyze the influential factors of the maximum number of passengers. The effect utilities and priority of different measures on improving the LOSWR are also discussed. Two-stage experiments are conducted to provide the results of the above analytical objectives. In the first stage, two significant factors are chosen to analyze their effects on the maximum number of passengers and the LOSWR. In the second stage, the effect utilities of different measures on improving the LOSWR are analyzed and their priority is provided based on the first stage.

This paper is organized as follows. In Section 2, based on establishing the arrival and departure modules, the models involving the maximum number of passengers and the LOSWR are proposed. Also, the Arena simulation modules are presented. The model application is given to demonstrate two significant factors' effects on the maximum number of passengers and the LOSWR, and the effect utilities and priority of different measures on improving the LOSWR are also illustrated in Section 3. We present the conclusions in Section 4 , followed by the acknowledgements and references.

\section{Methodology}

\subsection{Problem Description}

2.1.1. Railway Passenger Station Operation. Railway passenger station as a transit place is a dynamic and complex system which plays an important role in guaranteeing passengers' arrival and departure smoothly. A significant amount of resources and measures (both dynamic and static) is allocated in order to receive, accommodate, and dispatch passengers and provide essential services for passengers. Some service units include ticket hall, security check, waiting room, and human resources. The main purpose of railway passenger station is to meet different functional standards and realize their mutually complementary.

The moving process of passengers at a railway passenger station usually consists of three steps: arrival, waiting, and departure. The arrival step begins with passengers entering the gates and security checkpoints and ends when passengers arrive at the waiting room. Waiting step begins when passengers arrive at the waiting room and ends when they get on the trains by punching the tickets. This step is a bridge connecting passengers' arrival and departure. Departure step is marked by passengers' leaving by punching the tickets shortly before the train's departure. The operation process of different functional modules of railway passenger station is shown in Figure 1.

2.1.2. Waiting Room and the LOSWR. The waiting room of railway passenger station is the main place to provide the railway service for passengers and also the residence place before passengers leaving the station. Depending upon the waiting room's performance, the quality of the railway passenger station network operation may be ameliorated or aggravated.

The LOSWR also plays an important role in deciding the railway passenger station's level of service. It needs to be 


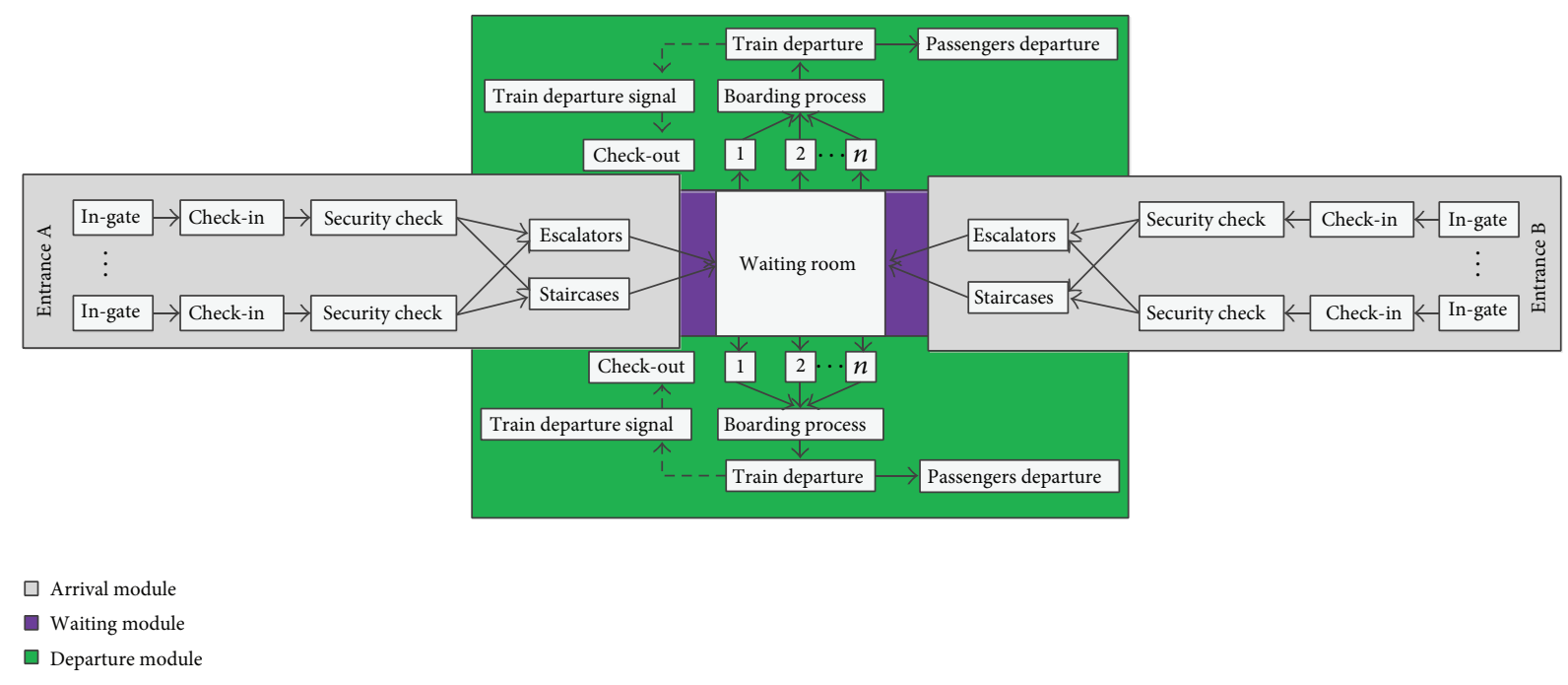

FIGURE 1: The operation process of different functional modules of railway passenger station.

analyzed thoroughly. The maximum number of passengers in waiting room is the main technical indicator in improving the level of service, as well as scale designing, amount of investment, and setting of related rooms; it also contributes to the passengers' satisfaction from the perspectives of per capita waiting area and walking environment, and so forth. Various factors can influence the LOSWR from passengers' arrival to departure. In this paper, we study these influential factors, the effect utilities, and priority of different measures on improving the LOSWR based on the arrival, waiting, and departure modules which are illustrated in Figure 1.

\subsection{Model Development}

\subsubsection{Definitions of Different Functional Modules}

(1) Arrival Module. This section emphasizes on the study of the rule of passengers' aggregation and calculation method of the maximum number of passengers in waiting room. Most passengers will arrive at the railway passenger station some time before the train's departure, and based on some related studies [17-19], we assume the passenger advanced arrival time obeys the lognormal distribution and its probability density function is as follows:

$$
f(t)= \begin{cases}\frac{1}{\sqrt{2 \pi} \sigma t} \exp \frac{-(\ln t-\mu)^{2}}{2 \sigma^{2}} & t>0 \\ 0 & t \leq 0\end{cases}
$$

where $t$ represents the passenger advanced arrival time and $\mu$ and $\sigma$ are the location and scale parameters of lognormal distribution, respectively, which can be obtained through the field surveys' data fitting.
Considering that all the passengers are supposed to arrive at the station before the train's departure, one condition should be met:

$$
\int_{t_{0}}^{t_{0}+T} f(t) \mathrm{d} t=1
$$

where $t_{0}$ is a fitted value that represents a particular moment before the train's departure and $T$ is the total time from the first to the last passenger's arrival time. According to the surveys and analyses, we set, in this study the value as 90 which means that all the passengers should arrive at railway passenger station within 90 minutes starting from the first passenger's arrival time and we regard it as a fixed value according to this paper [12].

Therefore, at a given time $t_{x}$, the proportion of arrived passengers taking train $j$ can be found as follows:

$$
P_{j}\left(t_{x}\right)=1-\int_{t_{0}}^{t_{0}+t_{x}} \frac{1}{\sqrt{2 \pi} \sigma t} \exp \frac{-(\ln t-\mu)^{2}}{2 \sigma^{2}} \mathrm{~d} t
$$

where $t_{x}$ represents a given time and $t_{x} \in\left(t_{0}, t_{0}+T\right)$ and $j$ is the train number and $j \in J$ ( $J$ represents the set of all the scheduled trains at railway passenger station).

In Figure $2, t_{j \text {-dpt }}$ represents the departure time of train $j$ and $t_{j \text {-first }}$ and $t_{j \text {-last }}$ represent the arrival time of the first and last passenger, respectively. Therefore, the difference of the above two time points is $T . t_{j-i}$ represents the arrival time of the $i$ th passenger and $t$ is the passenger advanced arrival time which obeys the lognormal distribution. The time analysis on passengers' arrival of waiting room is shown in Figure 2.

(2) Departure Module. For waiting rooms, the departure flow is mainly produced by the check-out passengers. Apparently, this step often occurs shortly before the train's departure. In general, a train's check-out time begins 20-30 minutes and ends 3-5 minutes prior to the train's departure time. In this paper we introduce $t_{c}$ to represent the advanced check-out time with respect to the train's departure time. 


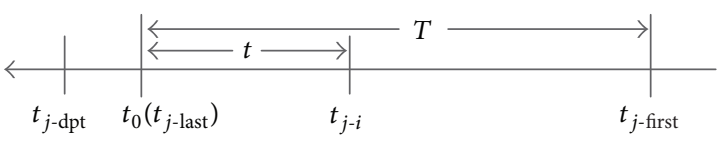

FIGURE 2: The time analysis on passengers' arrival of waiting room.

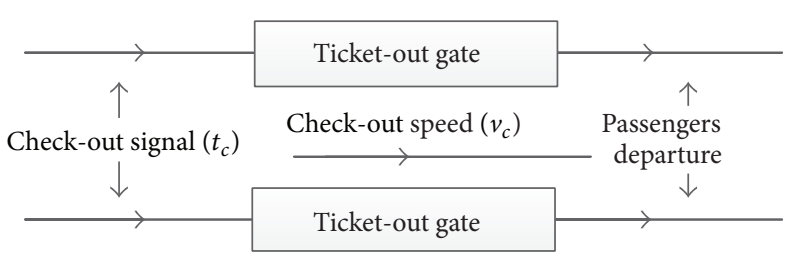

FIGURE 3: The operation process of departure module.

According to some surveys and related studies [12, 14], the check-out speed remains a constant for a certain period of time after the check-out signal begins. Then this value will decline with the extension of time. Given the fixed number of passengers of each train, we introduce $t_{d}$ to represent the check-out duration time and $v_{c}$ to represent the check-out speed. In this paper we consider the check-out speed as a constant within the check-out duration time.

For one train's departure, the station will open 2 or 3 ticket-out gates generally. In this paper we introduce $m_{g}$ to represent the number of ticket-out gates. The values of the above four parameters $\left(t_{c}, t_{d}, v_{c}\right.$, and $\left.m_{g}\right)$ will be given in Section 3.2.

The operation process of departure is shown in Figure 3.

\subsubsection{Evaluation Model of the LOSWR}

(1) Model of the Maximum Number of Passengers in Waiting Room. From the above analysis of passengers' arrival and departure, during the process of passengers' aggregation, arrival and departure may occur simultaneously at each given time $t_{x}$ for multiple trains. Consequently, the difference of the arrival flow and departure flow at given time $t_{x}$ is the number of aggregation passengers in the waiting room.

For the $j$ th train, the number of aggregation passengers at given time $t_{x}$ can be formulated as follows:

$$
N_{\text {train- } j}= \begin{cases}P_{j}\left(t_{x}\right) \cdot N_{\text {fixed }-j} \cdot \alpha_{\text {full }} \cdot\left(1+r_{a}\right)-\sum_{k=t_{j-\text { first }}}^{t_{x}} d_{k}-m_{g} \cdot v_{c} \cdot\left\{\max \left(t_{c}, t_{x}\right)-t_{c}\right\} & t_{x} \leq t_{c}+t_{d-j} \\ 0 & t_{x}>t_{c}+t_{d-j}\end{cases}
$$

subject to

$$
\begin{aligned}
& N_{\text {fixed }-j} \cdot \alpha_{\text {full }} \cdot r_{a}=\sum_{k=t_{j-\text { frist }}}^{t_{c}+t_{d-j}} d_{k}, \\
& N_{\text {fixed }-j} \cdot \alpha_{\text {full }}=m_{g} \cdot v_{c} \cdot t_{d-j}, \\
& P_{j}\left(t_{x}\right) \cdot N_{\text {fixed }-j} \cdot \alpha_{\text {full }} \cdot\left(1+r_{a}\right) \\
& \geq \sum_{k=t_{j-\text { frrt }}}^{t_{x}} d_{k}+m_{g} \cdot v_{c} \cdot\left\{\max \left(t_{c}, t_{x}\right)-t_{c}\right\}
\end{aligned}
$$

$$
t_{x} \leq t_{c}+t_{d-j}
$$

where $N_{\text {train- } j}$ is the number of aggregation passengers produced by the $j$ th train at a given time $t_{x}$ in $\left(t_{0}, t_{0}+T\right), N_{\text {fixed- } j}$ represents the fixed number of passengers of train $j, \alpha_{\text {full }}$ is the load factor of train $j$, and $r_{a}$ is the accompany rate that represents the number of passenger drop-offs accounts for one train. $t_{d-j}$ represents the check-out duration time of train $j$ and $d_{k}$ is the number of passenger drop-offs left in the $k$ th minute which varies with the values of $r_{a}$. In this paper, we assume the departure time of the passenger drop-offs obeys the uniform distribution on $\left[t_{j \text {-first }}, t_{c}+t_{d-j}\right]$. The definitions of $t_{c}, v_{c}$, and $m_{g}$ have been given in Section 2.2.1.
Therefore, at given time $t_{x}$ before the check-out time of train $h$, the number of aggregation passengers produced by all the waiting trains is

$$
K_{h}=\sum_{j \in I_{q}} N_{\text {train-j }}
$$

where $h$ represents one of the waiting trains, $I_{q}$ is the set of all the waiting trains that have not departed, and $I_{q} \subset J$.

Then, the maximum number of passengers in waiting room is

$$
K=\lambda \max _{h \in J}\left(K_{h}\right),
$$

where $J$ represents the set of all the scheduled trains at railway passenger station, including originating trains and passing trains, and $\lambda$ is the correction factor.

(2) Model of the LOSWR. The waiting room is a transit place which connects passengers' arrival and departure. The LOSWR is the most important factor, deciding the level of service at a railway passenger station. It also determines the passengers' satisfaction directly. Numerous studies have been conducted to evaluate the level of service at a railway passenger station, including its waiting room. But there is no standard to evaluate the LOSWR for the characteristics of regional and complex factors. 
TABLE 1: Fruin's level of service evaluation standard.

\begin{tabular}{lc}
\hline$F\left(\right.$ Pedestrian area $\left(\right.$ people $\left.\left./ \mathrm{m}^{2}\right)\right)$ & Level of service \\
\hline $0 \sim 0.31$ & A \\
$0.31 \sim 0.43$ & B \\
$0.43 \sim 0.72$ & C \\
$0.72 \sim 1.08$ & D \\
$1.08 \sim 2.17$ & E \\
$>2.17$ & F \\
\hline
\end{tabular}

The influential factors for the LOSWR in waiting room include the environment sanitation, as well as waiting environment condition, accuracy of train's information forecast, and organization of passengers' boarding the train. Flow density is the number of passengers in each unit area (density threshold: people $/ \mathrm{m}^{2}$ ), which is an important indicator to evaluate the pedestrian level of service. Given the area of waiting room and the maximum number of passengers found by Arena simulation, we adopt, in this paper, the Fruin evaluation index to evaluate the LOSWR from the perspective of passengers' satisfaction based on per capita waiting area and walking environment, and so forth. The method is as follows:

$$
F=\frac{K}{S},
$$

where $F$ represents the number of passengers in each unit area, $K$ is the maximum number of passengers in waiting room, and $S$ is the area of waiting room. Fruin's level of service evaluation standard is illustrated in Table 1.

2.3. The Research Methods and Steps. In order to evaluate the LOSWR, the Furin evaluation method based on passengers' satisfaction is adopted. For this purpose, two steps are included: firstly, the model of the maximum number of passengers in waiting room is established. Secondly, the Furin evaluation model is presented based on the maximum number of passengers in the waiting room.

To further analyze the LOSWR, the Arena simulation methodology is adopted to simulate passengers' aggregation behaviors in waiting room. For example, the influential factors of the LOSWR, the effect utilities, and priority of different measures on improving the LOSWR are all illustrated by using the simulation method in this study. Three steps are also included for the above objectives. Firstly, the Arena simulation model is constructed and validated by comparing the simulation results with the results of the model in Section 2.2.2. Secondly, two simulation scenarios are conducted to demonstrate two significant factors' effects on the maximum number of passengers and the LOSWR. Lastly, the effect utilities and priority of three different measures on improving the LOSWR are illustrated based on the simulation scenarios in the second step.

2.4. Simulation Concept and Process. The purpose of designing of the simulation system is to develop a methodology for studying the rule of passengers' aggregation in the railway passenger station waiting room. Therefore, the simulation system needs to meet the conditions [20] which are as follows: the system (1) can be used for the case analysis of different railway passenger stations; (2) can be changed relatively easily for meeting the needs of different users; and (3) can be maintained and developed conveniently.

In this study we adopt the object-oriented concept to model the simulation system, based on the above conditions. Through analyzing the common elements of different railway passenger stations, the functional modules at a passenger station need to be built in the simulation for different research purposes and objects. For example, the modules may include check-in, security check, and check-out. For each module, the simulation requires identifying its attributes. The last step is to connect the modules to reflect the operation in the waiting room.

In order to analyze the operation of railway passenger station and the process of passengers' aggregation, the system is programmed into a visual simulation modelling software called Arena [21]. Since the Arena software is a dynamic and visual system that can real-timely simulate the process of passengers' aggregation, the operators could take real-time or preventive measures to regulate passengers' aggregation and maintain the LOSWR at a higher grade. In Figure 4, a detailed scheme of operation process of railway passenger station is presented.

The simulation scenario is about the arrival, waiting, and departure of passengers at the railway passenger station. At first, passengers of each train are created to enter the railway station. The attributes of each train and its passengers based on the train departure information need to be initialized to make each created module unique. For example, the created module ought to be given its first passenger arrival time, number of passengers per arrival, and time between arrivals. After defining the created module, the behaviors of checkin and security check need to be determined. In the waiting room, passengers will aggregate with the process of arrival and departure. Based on the train departure information, passengers' departure begins under the settings of advanced check-out time, check-out duration time, check-out speed, and the number of ticket-out gates.

Since the simulation process of passengers' arrival and departure is carried out real-timely, the rule of passengers' aggregation could be obtained synchronously. After the simulation starts, statistical calculation will be performed along with the process of passengers' departure. For example, in this study, we collected the number of aggregation passengers and the maximum number of passengers in waiting room, which are the main performance indicators of the simulation system.

During the simulation, the most important events include the following:

(a) Passengers' arrival: when the passengers of a specific train are created, they will enter the designated waiting room and pass through the designated ticketout gates.

(b) Walking from security checkpoint to waiting room: a certain period of time will be accounted for this step 


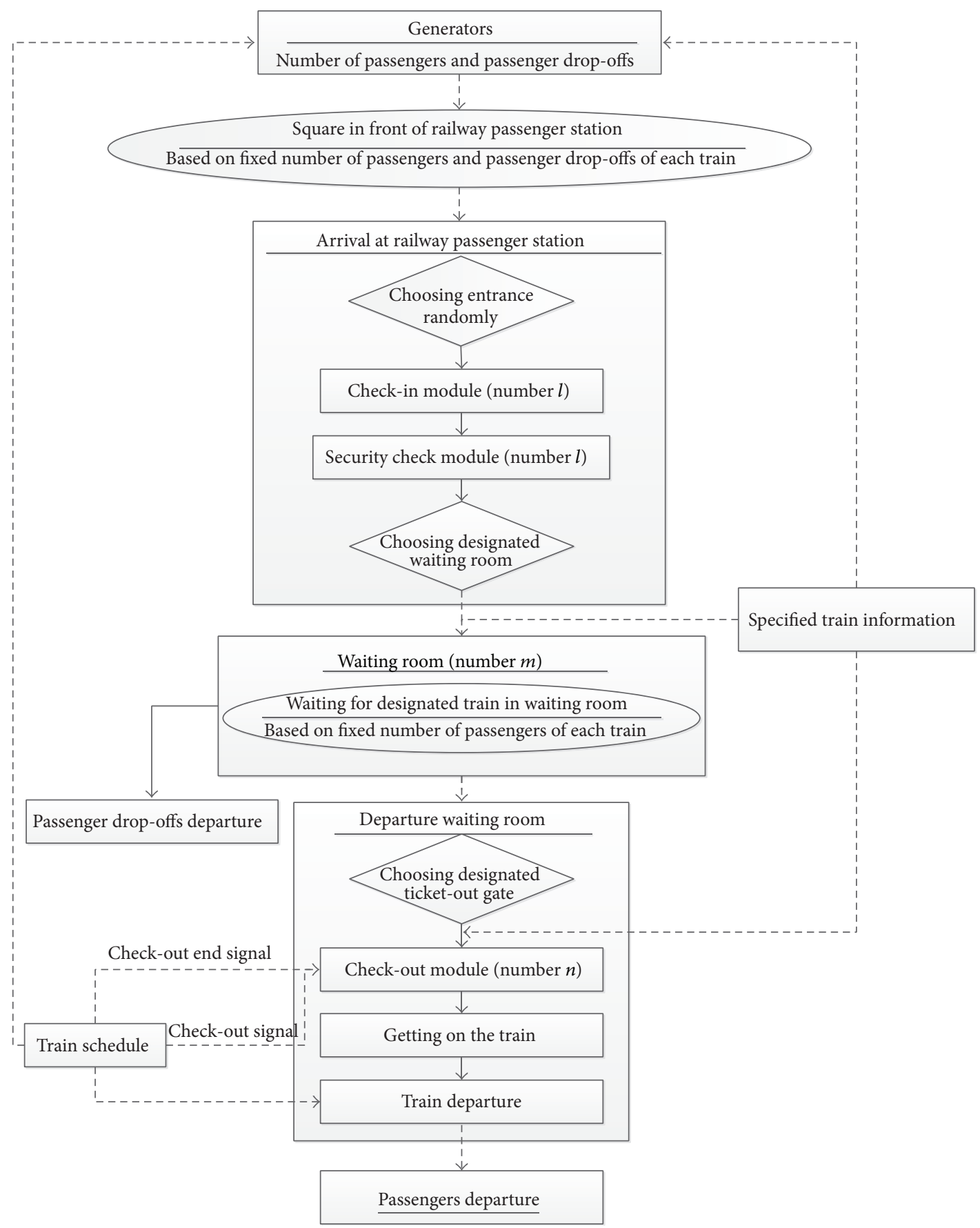

FIGURE 4: Simulation process of operation of railway passenger station.

(we set in this study that the value obeys the uniform distribution and the parameter value is (mean $=3$, std $=5)$ ).

(c) End of simulation: when predefined simulation time is up, statistical calculation data will be output (we design 10 simulation experiments and run each experiment 20 replications to get the results. And the replication length is set to 1 month).

(d) Later data processing: all the statistical data will be output to the designated file for postanalysis.
2.5. Establishment of Arena Simulation Modules. In simulating passengers' arrival, the first step is to create passengers' arrival, check-in, and security check modules, which have been defined in Section 2.2.1. Each created module will create the passenger flow which is consistent with the parameters of its corresponding waiting train, such as the train's departure time, first passenger arrival time, and time between arrivals. The number of created modules is determined by the number of waiting trains, since there exists one-to-one relationship between the created module and the departure module. 


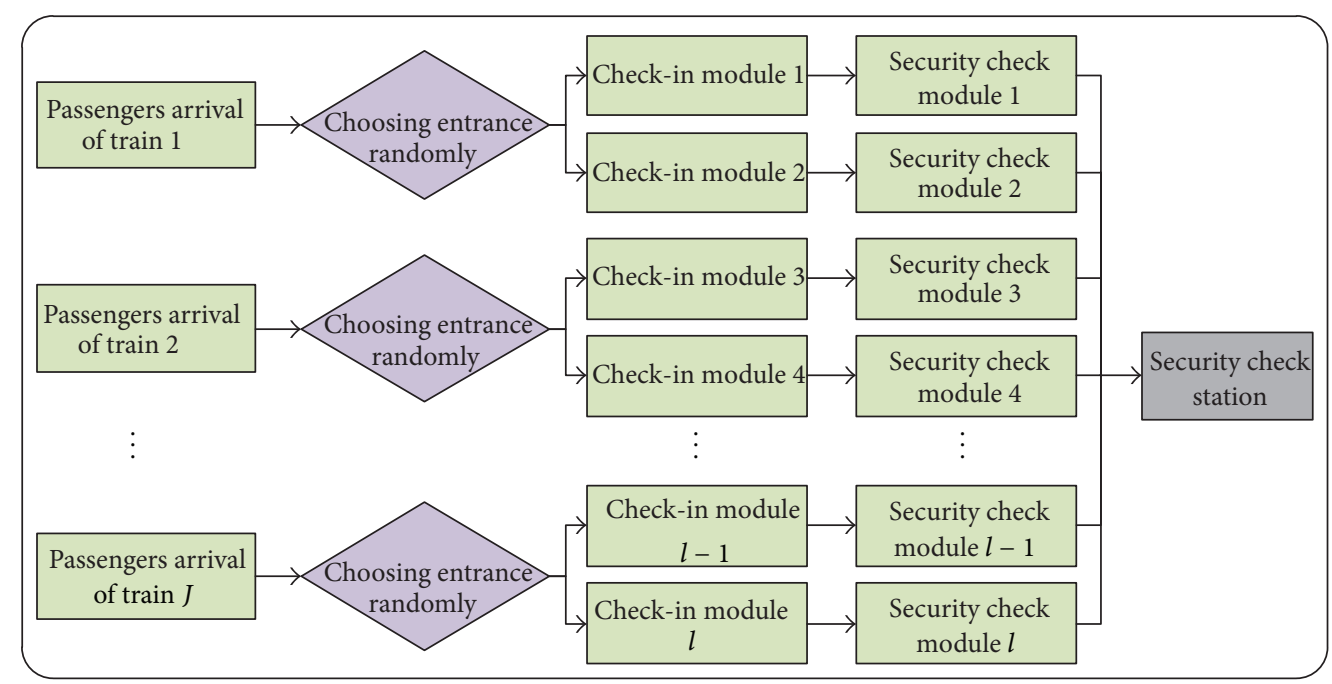

FIGURE 5: Arrival, check-in, and security check module.

TABLE 2: List of input parameters used in arrival, check-in, and security check module.

\begin{tabular}{|c|c|}
\hline $\begin{array}{l}\text { Classification of } \\
\text { input parameters }\end{array}$ & Name and meaning \\
\hline $\begin{array}{l}\text { Attributes of } \\
\text { passengers }\end{array}$ & $\begin{array}{l}\text { First passenger arrival time } \\
\text { Time between arrivals (assumed to obey the } \\
\text { exponential distribution) } \\
\text { Number of passengers per arrival (including } \\
\text { the number of passenger drop-offs) } \\
\text { Created modules' type (corresponding to the } \\
\text { trains' number) }\end{array}$ \\
\hline $\begin{array}{l}\text { Attributes of } \\
\text { railway } \\
\text { passenger } \\
\text { station }\end{array}$ & $\begin{array}{l}\text { Trains' departure time } \\
\text { The number of trains (originating trains and } \\
\text { passing trains) } \\
\text { Trains' numbers } \\
\text { Check-in speed } \\
\text { Security check speed }\end{array}$ \\
\hline
\end{tabular}

The check-in and security check modules determine the speed of check-in and security check, as shown in Figure 5. The definitions of input parameters are listed in Table 2.

From the security checkpoint to the waiting room, passengers will enter the designated waiting room by choosing staircases or taking escalators. A certain period of time will be taken in this process. In the simulation process, we take this period of time into consideration in order to be consistent with the actual situations.

The waiting and departure module consists of two submodules: waiting in line module and triggering signal module. In the first submodule, the Read step can read and output the number of aggregation passengers real-timely with the process of passengers' arrival and departure in waiting room. The Hold step receives the check-out signal and then releases passengers which represents the beginning of checkout. During passengers' aggregation, the passenger drop-offs will leave the waiting room and we assume the departure time of passenger drop-offs obeys the uniform distribution. All
TABLE 3: List of input parameters used in waiting and departure module.

\begin{tabular}{ll}
\hline $\begin{array}{l}\text { Classification of input } \\
\text { parameters }\end{array}$ & Name and meaning \\
\hline Waiting module & $\begin{array}{l}\text { The time taken from security } \\
\text { checkpoint to waiting room }\end{array}$ \\
\hline & TNOW (current time value) \\
& NQ (passengers in waiting room) \\
& Output file address \\
Waiting in line module & Waiting for check-out signal \\
& value (passengers) \\
& Waiting for departure signal \\
& value (passenger drop-offs) \\
\hline & Time between created signals \\
& First created signal arrival time \\
& Check-out signal value \\
& Departure signal value \\
& Check-out duration time \\
Triggering signal module & Check-out speed \\
& The number of ticket-out gates \\
\hline
\end{tabular}

of the above processes will continue until the end of checkout. The triggering signal module creates the departure signal for passenger drop-offs and check-out signal for passengers. The above two submodules mainly realize the functions of calculating the number of passengers in the waiting room and ensure passengers' departure by connection logically. The waiting and departure module and the definitions of input parameters are shown in Figure 6 and Table 3.

\section{Model Application}

In this section, we discuss the simulation scenario with sixty-two trains, scheduled in one day. Each train has an individual departure time. Meanwhile, two types of trains (originating trains and passing trains) are included, presented in Appendix. By simulating the operation process from 
TABLE 4: Values of simulation parameters and variables.

\begin{tabular}{|c|c|c|c|c|c|c|c|c|}
\hline \multirow[t]{2}{*}{ Parameters and variables type } & \multicolumn{3}{|c|}{ Passengers' arrival } & \multicolumn{5}{|c|}{ Railway passenger station's operation and management } \\
\hline & $\mu$ & $r_{a}$ & & $N_{\text {fixed- } j}$ & $\alpha_{\text {full }}$ & $J$ & $\lambda$ & $d_{k}$ \\
\hline & Variable & Variable & & $1100 / 400$ & 0.8 & 62 & 1.4 & $\begin{array}{c}\text { Nonfixed } \\
\text { value }\end{array}$ \\
\hline & $\sigma$ & $t_{0}$ & $T$ & $m_{g}$ & $t_{d}$ & $t_{c}$ & $v_{c}$ & $S$ \\
\hline & 0.34 & 3 & 90 & 2 & $15 / 5$ & Variable & Variable & Variable \\
\hline
\end{tabular}

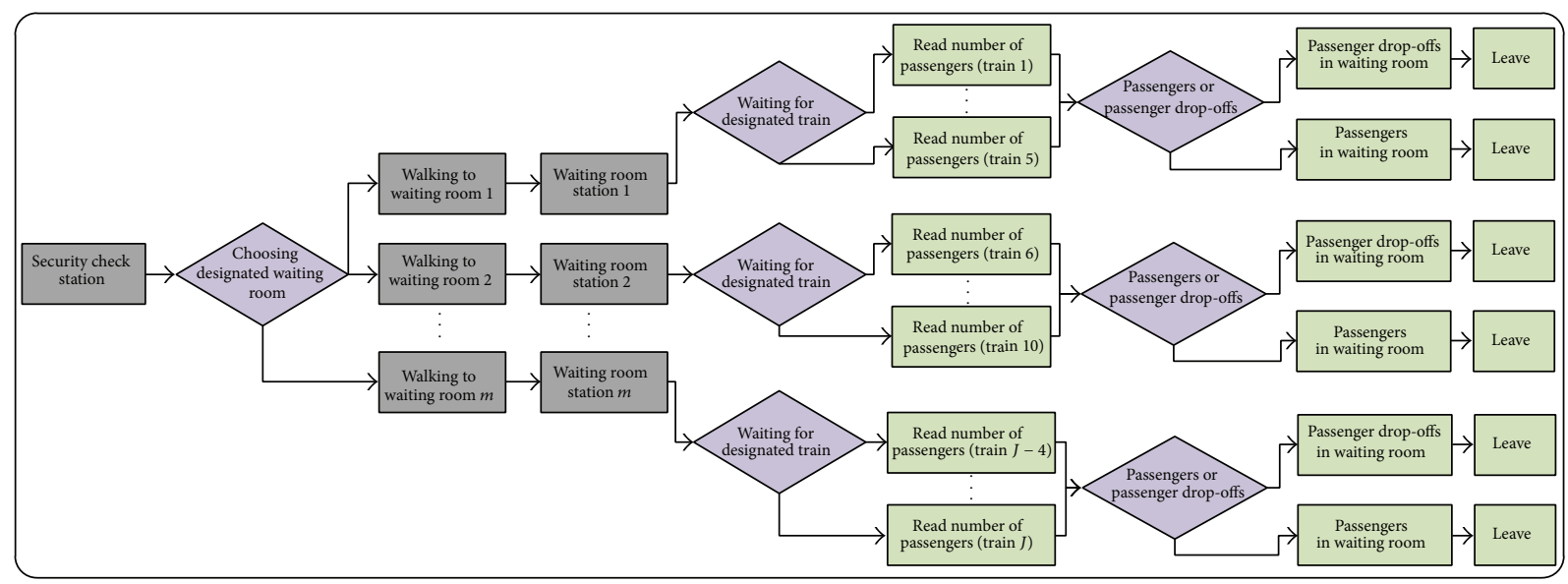

FIGURE 6: Waiting and departure module.

passengers' arrival to departure at the railway passenger station, passengers' aggregation behaviors in waiting room can be obtained based on the above simulation. Thus, the LOSWR based on the maximum number of passengers can be evaluated and analyzed.

The location parameter $\mu$ of the lognormal distribution represents the average value of the passenger advanced arrival time. The existing studies all assume that the passenger advanced arrival time is the main factor to influence the maximum number of passengers and the LOSWR $[10,22]$. Actually, various factors can also influence the passenger advanced arrival time, such as passengers' travel behaviors, types of passengers (from originating trains or passing trains), and travel time reliability which varies over different transportation arrival modes. In this section, we focus on the analysis of the passenger advanced arrival time denoted by $\mu$.

Accompany rate $r_{a}$ represents how much the number of passenger drop-offs accounts for the number of passengers for a specific train. For larger railway passenger stations, it is necessary to analyze the accompany rate because the number of passenger drop-offs influences significantly how passenger flow and the maximum number of passengers change. The greater the accompany rate, the greater the number of aggregation passengers and the maximum number of passengers in waiting room, causing lower LOSWR.

In the section, firstly, the location parameter and the accompany rate are chosen to analyze their effects on the maximum number of passengers and the LOSWR. Both of them are uncontrollable to the railway passenger station. Secondly, based on the above simulation results, sensitivity analysis results are provided and discussed to identify different measures' effect utilities and their priority on improving the LOSWR in order to provide the factual basis for operators taking measures to improve the LOSWR.

3.1. Parameters and Variables Setting. Based on the computer simulation, the value of $t_{0}$ equals 3 for better fitting results. The fixed numbers of passengers from originating trains and passing trains are set to 1100 and 400, respectively. Because the minimum value of $v_{c}$ is set to 40 people/minute, the number of ticket-out gates is 2 in this paper and the initial value of check-out duration time $\left(t_{d}\right)$ is set to 15 and 5 minutes, respectively, for the originating trains and passing trains. The train schedule is shown in Appendix. All the values of simulation parameters and variables are listed in Table 4.

3.2. Verification and Validation of the Simulation Model. Our simulation model has to verify whether it is working in the way it is planned. Above all, it is developed in three steps. And each step is examined individually. For example, the arrival step is developed and examined first before the other two steps. Secondly, we take advantage of the tracing approach, readily available in Arena simulation. Via tracing, we can know the whole life cycle of an entity and make comparison with the calculation results of the model of the maximum number of passengers in waiting room in Section 2.2.2. Finally, animation is also a useful way to visually verify our simulation model.

For validation purposes, we have run some simulation experiments based on the parameters and variables in Table 4 
TABLE 5: Calculation results of the model of the maximum number of passengers in waiting room and simulation results.

\begin{tabular}{lccc}
\hline \multicolumn{2}{c}{$\begin{array}{c}\text { Comparison } \\
\text { scenario }\end{array}$} & $\begin{array}{c}\text { Calculation results } \\
\text { of the model }\end{array}$ & $\begin{array}{c}\text { Simulation results } \\
\text { average (half-width } \\
95 \% \text { C.I) }\end{array}$ \\
\hline 2.87 & $r_{a}$ & 1086 & $1110( \pm 25)$ \\
3.37 & $0 \%$ & 3018 & $3064( \pm 37)$ \\
3.87 & $0 \%$ & 6497 & $6541( \pm 18)$ \\
3.37 & $10 \%$ & 3589 & $3595( \pm 11)$ \\
3.37 & $20 \%$ & 4147 & $4152( \pm 8)$ \\
3.37 & $30 \%$ & 4635 & $4674( \pm 21)$ \\
\hline
\end{tabular}

TABLE 6: The simulation scenarios of the basic experiment.

\begin{tabular}{lccc}
\hline Independent variable & Simulation scenario & $\mu$ & $r_{a}$ \\
\hline \multirow{3}{*}{ Passenger advanced arrival time } & 1 & 2.87 & $0 \%$ \\
& 2 & 3.37 & $0 \%$ \\
& 3 & 3.87 & $0 \%$ \\
\hline \multirow{3}{*}{ Accompany rate } & 1 & 3.37 & $0 \%$ \\
& 2 & 3.37 & $5 \%$ \\
& 3 & 3.37 & $10 \%$ \\
& 4 & 3.37 & $15 \%$ \\
& 5 & 3.37 & $20 \%$ \\
& 6 & 3.37 & $25 \%$ \\
& 7 & 3.37 & $30 \%$ \\
\hline
\end{tabular}

$t_{c}=20$ (minutes), $v_{c}=40$ (people/minute), $S=4500$ (square meters).

and Appendix. We run the simulation model for 20 replications with each replication lasting for 1 month and get the results under 0.95 confidence level. As shown in Table 5, the main performance indicator is the maximum number of passengers in waiting room from 6:00 am to $22: 00 \mathrm{pm}$ in one day.

As a result of the comparisons between simulation results and calculation results of the model of the maximum number of passengers in waiting room, the simulation model built for the operation process of the railway passenger station is considered to be close to the actual system, which enables us to perform more analysis.

3.3. The Simulation Results of the Basic Experiment. Since the model has been constructed and validated, we can use it to design experiments and analyze the passenger advanced arrival time and the accompany rate's effects on the maximum number of passengers and the LOSWR in different situations for the purpose of effect utility analysis. In this study, we design 10 simulation experiments and run each experiment 20 replications to get the results under 0.95 confidence level. And the replication length is set to 1 month. The simulation scenarios of the basic experiment are shown in Table 6 .

\subsubsection{The Simulation Results of the Passenger Advanced Arrival} Time. According to the analysis shown in Table 6, it appears that different values of the passenger advanced arrival time could lead to different values of the maximum number

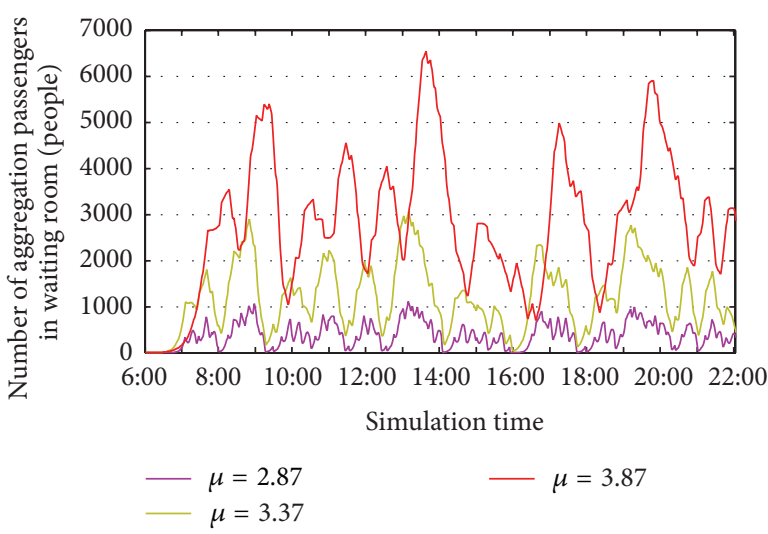

FIGURE 7: The number of aggregation passengers varies over the values of the passenger advanced arrival time.

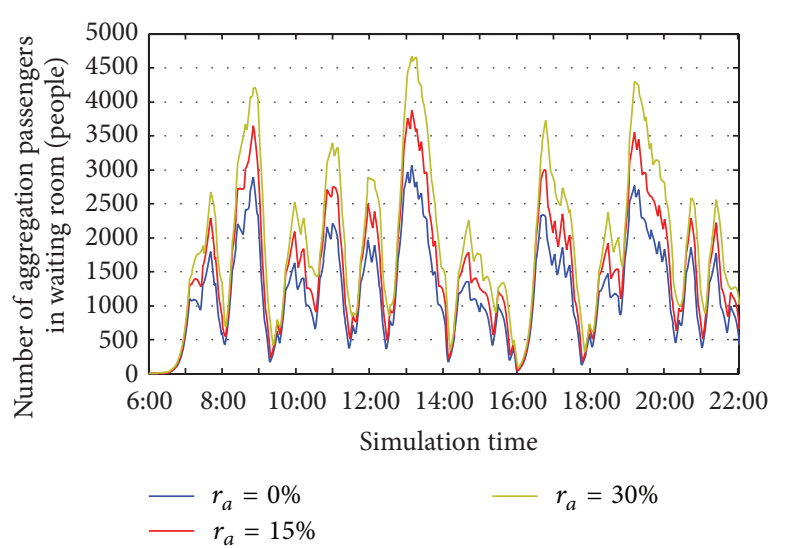

FIGURE 8: The number of aggregation passengers varies over the values of the accompany rate.

of passengers and the LOSWR. To make the effect utility analysis, we set the simulation time to 6:00 to 22:00. We also design three scenarios in which the values of $\mu$ are 2.87, 3.37, and 3.87, and the levels of service in waiting room are A, C, and $\mathrm{E}$ correspondingly $\left(r_{a}=0 \%\right)$. The simulation results are shown in Figure 7 and Table 7.

3.3.2. The Simulation Results of the Accompany Rate. In order to find the effect of the accompany rate on the maximum number of passengers and the LOSWR, we design seven scenarios where the minimum interval of $r_{a}$ is $5 \%\left(\Delta r_{a}=5 \%\right)$. Because the LOSWR is D when the interval of $r_{a}$ is $(5 \%, 30 \%)$, we just illustrate the scenarios of $r_{a}=0 \%, r_{a}=15 \%$, and $r_{a}=30 \%$ in Figure $8(\mu=3.37)$. The simulation results are shown in Figure 8 and Table 8.

3.4. The Analysis of Different Measures' Effect Utilities on Improving the LOSWR. For the railway passenger station, the check modes for passengers' departure and the scheme of the size of the waiting room are controllable factors and have significant influences on the maximum number of passengers and the LOSWR. In this section, we focus on the effect 
TABLE 7: The simulation results of railway passenger station waiting room $(\mu)$.

\begin{tabular}{lcccccc}
\hline Scenario & \multicolumn{2}{c}{$\begin{array}{c}\text { The location parameter of } \\
\text { lognormal distribution } \\
\text { Advanced arrival time }\end{array}$} & Average value & Increased proportion & Density threshold & LOSWR \\
\hline 1 & $\mu$ & 18.7 & 1110 & - & 0.25 & A \\
2 & 2.87 & 29.5 & 3064 & $176.0 \%$ & 0.68 & $\mathrm{C}$ \\
3 & 3.37 & 51.0 & 6541 & $113.5 \%$ & $\mathrm{E}$ \\
\hline
\end{tabular}

TABLE 8: The simulation results of railway passenger station waiting room $\left(r_{a}\right)$.

\begin{tabular}{|c|c|c|c|c|c|}
\hline \multirow{2}{*}{ Scenario } & \multirow{2}{*}{$\begin{array}{c}\text { Accompany rate } \\
r_{a} \\
\end{array}$} & \multicolumn{2}{|c|}{ Maximum number of passengers } & \multicolumn{2}{|c|}{ Flow density } \\
\hline & & Average value & Increased proportion & Density threshold & LOSWR \\
\hline 1 & $0 \%$ & 3064 & - & 0.68 & $\mathrm{C}$ \\
\hline 2 & $5 \%$ & 3325 & $8.5 \%$ & 0.74 & $\mathrm{D}$ \\
\hline 3 & $10 \%$ & 3595 & $8.1 \%$ & 0.80 & $\mathrm{D}$ \\
\hline 4 & $15 \%$ & 3873 & $7.7 \%$ & 0.86 & $\mathrm{D}$ \\
\hline 5 & $20 \%$ & 4152 & $7.2 \%$ & 0.92 & $\mathrm{D}$ \\
\hline 6 & $25 \%$ & 4422 & $6.5 \%$ & 0.98 & $\mathrm{D}$ \\
\hline 7 & $30 \%$ & 4674 & $5.7 \%$ & 1.04 & $\mathrm{D}$ \\
\hline
\end{tabular}

utilities of the advanced check-out time $\left(t_{c}\right)$, check-out speed $\left(v_{c}\right)$, the number of ticket-out gates $\left(m_{q}\right)$, and the area of waiting room $(S)$ on improving the LOSWR. For the check modes for passengers' departure, we concern advanced check-out time and check-out speed which represent $t_{c}, v_{c}$, and $m_{g}$, because the number of ticket-out gates and check-out speed mainly determine the number of passengers departed per unit time. The value of $t_{d}$ will be adjusted with respect to the changes of $t_{c}$ and $v_{c}$ in the following simulations.

3.4.1. The Analysis of the Effect Utilities Based on the Location Parameter $\mu$ of Lognormal Distribution. As illustrated in Table 7, the LOSWR reaches A when $\mu=2.87$. It becomes $\mathrm{C}$ when $\mu=3.37$ and the average advanced arrival time is 29.5 minutes. When $\mu=3.87$, the average advanced arrival time is 51.0 minutes and the LOSWR drops to E $\left(r_{a}=0 \%\right)$. Therefore, we only study how to improve the LOSWR about the two latter scenarios with the above three measures $\left(t_{c}, v_{c}\right.$, and $S$ ).

In the simulation, for the first two measures, the maximum number of passengers in waiting room decreases with the increases of advanced check-out time and check-out speed. However, the advanced check-out time has a stronger effect on reducing the maximum number of passengers than the check-out speed. Figure 9 shows the trend of the maximum number of passengers varies over the values of $t_{c}$ and $v_{c}$.

For improving the LOSWR illustrated in Table 9, the LOSWR shows an improved tendency in both scenarios with the increases of advanced arrival time and check-out speed. In the left part, when $\mu$ is less, the advanced check-out time improves the LOSWR stronger than the check-out speed. However, this trend stops as the value of $\mu$ increases from 3.37 to 3.87. On one hand, the whole LOSWR is lower when $\mu=3.87$. On the other hand, the improvement in the LOSWR

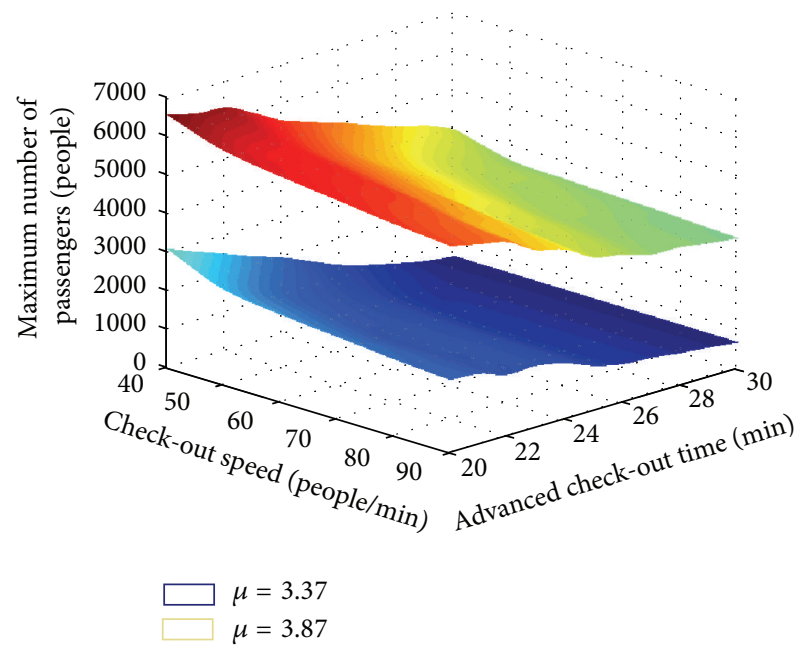

FIGURE 9: The maximum number of passengers in waiting room varies over the values of $t_{c}$ and $v_{c}$.

is less sensitive than the first scenario with respect to the changes of $t_{c}$ and $v_{c}$.

However, the LOSWR maintains at $\mathrm{C}$ and $\mathrm{E}$ when $\mu$ is 3.37 and 3.87, respectively, when the area of waiting room increases by $5 \%$ to $30 \%$, as illustrated in Table 10 . However, the LOSWR is much less sensitive to the change of $S$ comparing with the above two measures when the density threshold decreases.

3.4.2. The Analysis of the Effect Utilities Based on the Accompany Rate $r_{a}$. As illustrated in Table 8, the maximum number of passengers in the waiting room increases as the accompany rate $\left(r_{a}\right)$ increases. Three measures are also analyzed about their effect utilities on the maximum number of passengers and improving the LOSWR. 
TABLE 9: The LOSWR varies over the values of $t_{c}$ and $v_{c}(\mu)$.

\begin{tabular}{|c|c|c|c|c|c|c|c|c|c|c|c|c|}
\hline \multirow{3}{*}{ Check-out speed } & \multicolumn{6}{|c|}{$\mu=3.37$} & \multicolumn{6}{|c|}{$\mu=3.87$} \\
\hline & 40 & 50 & 60 & 70 & 80 & 90 & 40 & 50 & 60 & 70 & 80 & 90 \\
\hline & \multicolumn{12}{|c|}{ LOSWR } \\
\hline \multicolumn{13}{|c|}{ Advanced check-out time } \\
\hline 20 & $\mathrm{C}$ & $\mathrm{C}$ & $\mathrm{C}$ & $\mathrm{C}$ & $\mathrm{C}$ & $\mathrm{B}$ & $\mathrm{E}$ & $\mathrm{E}$ & $\mathrm{E}$ & $\mathrm{E}$ & $\mathrm{E}$ & $\mathrm{E}$ \\
\hline 21 & $\mathrm{C}$ & $\mathrm{C}$ & $\mathrm{C}$ & $\mathrm{B}$ & $\mathrm{B}$ & $\mathrm{B}$ & $\mathrm{E}$ & $\mathrm{E}$ & $\mathrm{E}$ & $\mathrm{E}$ & $\mathrm{E}$ & $\mathrm{E}$ \\
\hline 22 & $\mathrm{C}$ & $\mathrm{C}$ & $\mathrm{B}$ & B & B & $\mathrm{B}$ & $\mathrm{E}$ & $\mathrm{E}$ & $\mathrm{E}$ & $\mathrm{E}$ & $\mathrm{E}$ & $\mathrm{E}$ \\
\hline 23 & $\mathrm{C}$ & $\mathrm{B}$ & $\mathrm{B}$ & $\mathrm{B}$ & $\mathrm{B}$ & $\mathrm{B}$ & $\mathrm{E}$ & $\mathrm{E}$ & E & $\mathrm{E}$ & $\mathrm{D}$ & $\mathrm{D}$ \\
\hline 24 & C & B & B & B & B & B & $\mathrm{E}$ & $\mathrm{E}$ & $\mathrm{E}$ & $\mathrm{D}$ & $\mathrm{D}$ & D \\
\hline 25 & B & $\mathrm{A}$ & A & A & A & A & $\mathrm{E}$ & $\mathrm{D}$ & $\mathrm{D}$ & $\mathrm{D}$ & $\mathrm{D}$ & D \\
\hline 26 & A & $\mathrm{A}$ & A & A & A & A & $\mathrm{E}$ & $\mathrm{D}$ & $\mathrm{D}$ & $\mathrm{D}$ & $\mathrm{D}$ & D \\
\hline 27 & A & $\mathrm{A}$ & A & A & A & A & $\mathrm{D}$ & $\mathrm{D}$ & $\mathrm{D}$ & $\mathrm{D}$ & $\mathrm{D}$ & D \\
\hline 28 & A & $\mathrm{A}$ & A & A & A & A & $\mathrm{D}$ & $\mathrm{D}$ & $\mathrm{D}$ & $\mathrm{D}$ & $\mathrm{D}$ & D \\
\hline 29 & A & A & A & A & A & A & $\mathrm{D}$ & $\mathrm{D}$ & $\mathrm{D}$ & $\mathrm{D}$ & $\mathrm{D}$ & $\mathrm{D}$ \\
\hline 30 & A & A & A & A & A & A & $\mathrm{D}$ & $\mathrm{D}$ & $\mathrm{D}$ & $\mathrm{D}$ & $\mathrm{D}$ & $\mathrm{D}$ \\
\hline
\end{tabular}

TABLE 10: The LOSWR varies over the value of $S(\mu)$.

\begin{tabular}{|c|c|c|c|c|c|}
\hline \multirow{2}{*}{$S$} & \multirow{2}{*}{ Increased proportion } & \multicolumn{2}{|c|}{$\mu=3.37$} & \multicolumn{2}{|c|}{$\mu=3.87$} \\
\hline & & Density threshold & LOSWR & Density threshold & LOSWR \\
\hline 4500 & - & 0.68 & $\mathrm{C}$ & 1.45 & $\mathrm{E}$ \\
\hline 4725 & $5 \%$ & 0.65 & $\mathrm{C}$ & 1.38 & $\mathrm{E}$ \\
\hline 4950 & $10 \%$ & 0.62 & $\mathrm{C}$ & 1.32 & $\mathrm{E}$ \\
\hline 5175 & $15 \%$ & 0.59 & $\mathrm{C}$ & 1.26 & $\mathrm{E}$ \\
\hline 5400 & $20 \%$ & 0.57 & $\mathrm{C}$ & 1.21 & $\mathrm{E}$ \\
\hline 5625 & $25 \%$ & 0.54 & $\mathrm{C}$ & 1.16 & $\mathrm{E}$ \\
\hline 5850 & $30 \%$ & 0.52 & $\mathrm{C}$ & 1.12 & $\mathrm{E}$ \\
\hline
\end{tabular}

For the maximum number of passengers, comparing to Section 3.4.1, both the advanced check-out time and checkout speed have a stronger effect on reducing the maximum number of passengers in the three scenarios $\left(r_{a}=0 \%, 15 \%\right.$, and 30\%). Between advanced check-out time and check-out speed, advanced check-out time has the stronger effect utility, as shown in Figure 10.

A great similarity is found among the three scenarios $\left(r_{a}=0 \%, 15 \%\right.$, and 30\%) with the LOSWR varying over the values of advanced check-out time and check-out speed. Both the advanced check-out time and check-out speed have strong effect utilities on improving the LOSWR which is different from the situation where $\mu=3.87$ in Table 9. Since the advanced check-out time becomes the dominant factor on influencing the LOSWR and the accompany rate has a much weaker effect on improving the LOSWR. The situation where $r_{a}=0 \%$ is similar to the scenario where $\mu=3.37$ in Table 9 , so we only list the situations of $r_{a}=15 \%$ and $r_{a}=30 \%$. The LOSWR varies over the values of $t_{c}$ and $v_{c}$ with two different accompany rates as shown in Table 11.

Similar to the situation in Table 10, the LOSWR almost maintains at $\mathrm{D}$ with the area of waiting room increased by $5 \%$ to $30 \%$ where $r_{a}=15 \%$ and $r_{a}=30 \%$, as illustrated in Table 12. The LOSWR is also the least sensitive to the change of $S$ comparing with the above two measures. We can conclude that the advanced check-out time has the strongest effect utility on improving the LOSWR, the check-out speed has the secondary effect utility and the area of waiting room has the weakest effect utility. Therefore, for providing the factual basis for operators taking measures to improve the LOSWR, the priority of the above three measures $\left(t_{c}, v_{c}\right.$ and $S$ ) is advanced check-out time, check-out speed, and the area of waiting room.

\section{Discussion}

The simulation can be used to explore the passenger advanced arrival time and accompany rate's effects on the maximum number of passengers and the LOSWR. The effect utilities and their priority of advanced check-out time, check-out speed, and the area of waiting room on improving the LOSWR are also illustrated.

Based on the simulation scenario provided in Appendix, as well as the related parameters and variables in Table 4, six comparison scenarios are firstly conducted to validate the constructed simulation model. Thus we could use it to design more experiments for evaluating and analyzing the LOSWR.

In regard to assessing the effects of the passenger advanced arrival time and accompany rate on the maximum number of passengers and the LOSWR, the simulation method is able to perform a quantitative analysis of two significant uncontrollable factors' influences on the maximum 
TABLE 11: The LOSWR varies over the values of $t_{c}$ and $v_{c}\left(r_{a}\right)$.

\begin{tabular}{|c|c|c|c|c|c|c|c|c|c|c|c|c|}
\hline \multirow{3}{*}{ Check-out speed } & \multicolumn{6}{|c|}{$r_{a}=15 \%$} & \multicolumn{6}{|c|}{$r_{a}=30 \%$} \\
\hline & 40 & 50 & 60 & 70 & 80 & 90 & 40 & 50 & 60 & 70 & 80 & 90 \\
\hline & \multicolumn{12}{|c|}{ LOSWR } \\
\hline \multicolumn{13}{|c|}{ Advanced check-out time } \\
\hline 20 & $\mathrm{D}$ & $\mathrm{D}$ & $\mathrm{C}$ & $\mathrm{C}$ & $\mathrm{C}$ & $\mathrm{C}$ & $\mathrm{D}$ & $\mathrm{D}$ & $\mathrm{D}$ & $\mathrm{C}$ & $\mathrm{C}$ & $\mathrm{C}$ \\
\hline 21 & $\mathrm{D}$ & $\mathrm{C}$ & $\mathrm{C}$ & $\mathrm{C}$ & $\mathrm{C}$ & $\mathrm{B}$ & $\mathrm{D}$ & $\mathrm{D}$ & $\mathrm{C}$ & $\mathrm{C}$ & $\mathrm{C}$ & $\mathrm{C}$ \\
\hline 22 & $\mathrm{D}$ & $\mathrm{C}$ & $\mathrm{C}$ & $\mathrm{C}$ & B & $\mathrm{B}$ & $\mathrm{D}$ & $\mathrm{C}$ & $\mathrm{C}$ & $\mathrm{C}$ & $\mathrm{C}$ & B \\
\hline 23 & $\mathrm{C}$ & $\mathrm{C}$ & $\mathrm{C}$ & $\mathrm{B}$ & $\mathrm{B}$ & $\mathrm{B}$ & $\mathrm{D}$ & $\mathrm{C}$ & $\mathrm{C}$ & B & $\mathrm{B}$ & B \\
\hline 24 & $\mathrm{C}$ & $\mathrm{C}$ & B & B & B & $\mathrm{B}$ & $\mathrm{C}$ & $\mathrm{C}$ & $\mathrm{B}$ & $\mathrm{B}$ & $\mathrm{B}$ & A \\
\hline 25 & $\mathrm{C}$ & $\mathrm{C}$ & B & B & $\mathrm{A}$ & $\mathrm{A}$ & $\mathrm{C}$ & $\mathrm{C}$ & $\mathrm{B}$ & A & $\mathrm{A}$ & A \\
\hline 26 & $\mathrm{C}$ & $\mathrm{B}$ & A & $\mathrm{A}$ & $\mathrm{A}$ & $\mathrm{A}$ & $\mathrm{C}$ & $\mathrm{B}$ & $\mathrm{A}$ & A & $\mathrm{A}$ & A \\
\hline 27 & $\mathrm{~B}$ & $\mathrm{~A}$ & A & $\mathrm{A}$ & $\mathrm{A}$ & $\mathrm{A}$ & $\mathrm{C}$ & $\mathrm{B}$ & $\mathrm{A}$ & A & $\mathrm{A}$ & A \\
\hline 28 & A & $\mathrm{A}$ & A & $\mathrm{A}$ & $\mathrm{A}$ & $\mathrm{A}$ & $\mathrm{B}$ & $\mathrm{A}$ & $\mathrm{A}$ & A & $\mathrm{A}$ & A \\
\hline 29 & $\mathrm{~A}$ & $\mathrm{~A}$ & A & $\mathrm{A}$ & $\mathrm{A}$ & $\mathrm{A}$ & B & $\mathrm{A}$ & $\mathrm{A}$ & A & $\mathrm{A}$ & A \\
\hline 30 & $\mathrm{~A}$ & $\mathrm{~A}$ & A & $\mathrm{A}$ & $\mathrm{A}$ & $\mathrm{A}$ & $\mathrm{A}$ & $\mathrm{A}$ & $\mathrm{A}$ & $\mathrm{A}$ & $\mathrm{A}$ & $\mathrm{A}$ \\
\hline
\end{tabular}

TABLE 12: The LOSWR varies over the value of $S\left(r_{a}\right)$.

\begin{tabular}{|c|c|c|c|c|c|}
\hline \multirow{2}{*}{$S$} & \multirow{2}{*}{ Increased proportion } & \multicolumn{2}{|c|}{$r_{a}=15 \%$} & \multicolumn{2}{|c|}{$r_{a}=30 \%$} \\
\hline & & Density threshold & LOSWR & Density threshold & LOSWR \\
\hline 4500 & - & 0.86 & $\mathrm{D}$ & 1.04 & $\mathrm{D}$ \\
\hline 4725 & $5 \%$ & 0.82 & $\mathrm{D}$ & 0.99 & $\mathrm{D}$ \\
\hline 4950 & $10 \%$ & 0.78 & $\mathrm{D}$ & 0.94 & $\mathrm{D}$ \\
\hline 5175 & $15 \%$ & 0.75 & $\mathrm{D}$ & 0.90 & $\mathrm{D}$ \\
\hline 5400 & $20 \%$ & 0.72 & $\mathrm{D}$ & 0.87 & $\mathrm{D}$ \\
\hline 5625 & $25 \%$ & 0.69 & $\mathrm{C}$ & 0.83 & $\mathrm{D}$ \\
\hline 5850 & $30 \%$ & 0.66 & $\mathrm{C}$ & 0.80 & $\mathrm{D}$ \\
\hline
\end{tabular}

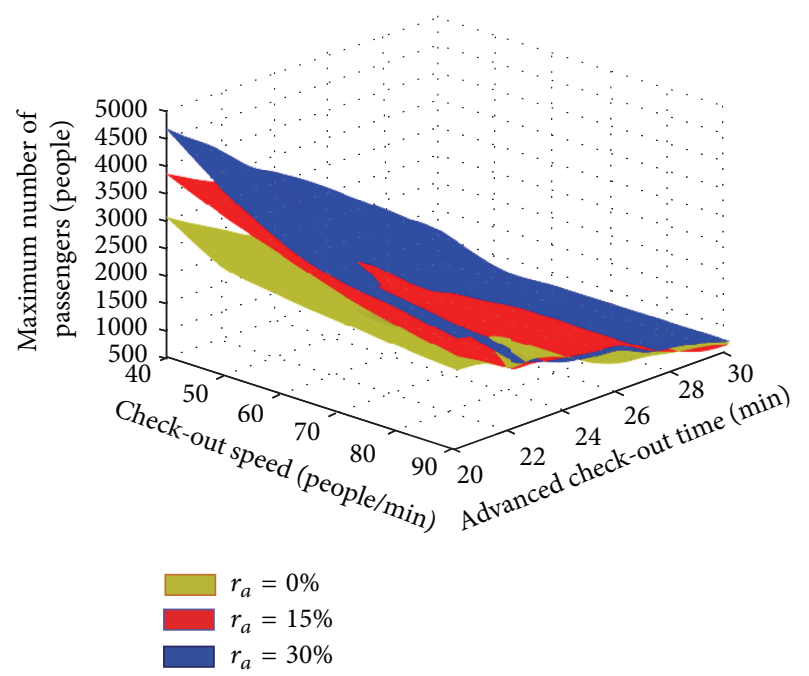

FIGURE 10: The maximum number of passengers in waiting room varies over the values of $t_{c}$ and $v_{c}$.

number of passengers and the LOSWR. Firstly, passenger advanced arrival time has a strong effect utility on the maximum number of passengers and the LOSWR. It appears that the predictable travel time is the key to predict the passenger advanced arrival time. It is necessary for railway passenger station to consider the travel time reliability which influences the passenger advanced arrival time in designing the waiting room of newly built passenger dedicated lines and maintaining the LOSWR at a higher grade. Secondly, accompany rate has a weaker influence on the maximum number of passengers and the LOSWR, but investigating the accompany rate is helpful to formulate the passenger organization plans and improve the LOSWR.

The simulation also demonstrates that, among the different measures which could be used to improve the LOSWR, the advanced check-out time has a much stronger effect utility on improving the LOSWR than the check-out speed and the area of waiting room. However, when passenger advanced arrival time becomes the dominant factor influencing the LOSWR, the advanced check-out time and check-out speed have a weaker effect utility on improving the LOSWR. As to the area of waiting room, it always has the weakest effect utility on improving the LOSWR. We can conclude that the priority of the above three measures on improving the LOSWR is advanced check-out time, check-out speed, and the area of waiting room.

Conducted experiments on the above simulation scenarios show the benefit of using the highly detailed simulation model to mimic the operation process from passengers' arrival to departure, better real-time passengers' aggregation behaviors in waiting room are achieved, and the LOSWR based on the maximum number of passengers is analyzed thoroughly. The validation experiments prove the reliability of the proposed simulation model, which could enhance the effectiveness of the conclusions derived from the simulation 
TABLE 13

\begin{tabular}{|c|c|c|}
\hline Number & $\begin{array}{c}\text { Number of passengers } \\
\text { dispatched }\end{array}$ & Departure time \\
\hline 1 & 1100 & $6: 32$ \\
\hline 2 & 1100 & $6: 55$ \\
\hline 3 & 1100 & $7: 08$ \\
\hline 4 & 400 & $7: 17$ \\
\hline 5 & 400 & $7: 28$ \\
\hline 6 & 1100 & $7: 45$ \\
\hline 7 & 1100 & $7: 55$ \\
\hline 8 & 1100 & 8:08 \\
\hline 9 & 1100 & $8: 16$ \\
\hline 10 & 1100 & $8: 21$ \\
\hline 11 & 1100 & $8: 30$ \\
\hline 12 & 400 & 9:02 \\
\hline 13 & 1100 & $9: 17$ \\
\hline 14 & 1100 & $9: 32$ \\
\hline 15 & 1100 & $10: 15$ \\
\hline 16 & 1100 & $10: 28$ \\
\hline 17 & 1100 & $10: 37$ \\
\hline 18 & 1100 & $10: 46$ \\
\hline 19 & 400 & $11: 12$ \\
\hline 20 & 1100 & $11: 25$ \\
\hline 21 & 1100 & $11: 38$ \\
\hline 22 & 1100 & $11: 49$ \\
\hline 23 & 400 & $11: 58$ \\
\hline 24 & 400 & $12: 16$ \\
\hline 25 & 1100 & $12: 29$ \\
\hline 26 & 1100 & $12: 39$ \\
\hline 27 & 1100 & $12: 45$ \\
\hline 28 & 1100 & $12: 53$ \\
\hline 29 & 1100 & 13:01 \\
\hline 30 & 1100 & 13:09 \\
\hline 31 & 1100 & $13: 18$ \\
\hline 32 & 1100 & $13: 33$ \\
\hline 33 & 400 & $13: 50$ \\
\hline 34 & 1100 & $14: 13$ \\
\hline 35 & 1100 & $14: 30$ \\
\hline 36 & 1100 & $14: 51$ \\
\hline 37 & 1100 & $15: 20$ \\
\hline 38 & 400 & $15: 47$ \\
\hline 39 & 1100 & $16: 25$ \\
\hline 40 & 1100 & $16: 33$ \\
\hline 41 & 1100 & $16: 42$ \\
\hline 42 & 1100 & $16: 57$ \\
\hline 43 & 1100 & $17: 10$ \\
\hline 44 & 1100 & $17: 23$ \\
\hline 45 & 400 & $17: 57$ \\
\hline 46 & 1100 & $18: 13$ \\
\hline 47 & 1100 & $18: 29$ \\
\hline 48 & 400 & $18: 46$ \\
\hline 49 & 1100 & $18: 57$ \\
\hline 50 & 1100 & $19: 06$ \\
\hline 51 & 1100 & $19: 14$ \\
\hline 52 & 1100 & $19: 21$ \\
\hline 53 & 1100 & $19: 33$ \\
\hline 54 & 1100 & $19: 42$ \\
\hline 55 & 1100 & $19: 56$ \\
\hline 56 & 1100 & $20: 05$ \\
\hline 57 & 400 & $20: 30$ \\
\hline 58 & 1100 & $20: 42$ \\
\hline
\end{tabular}

TABLE 13: Continued.

\begin{tabular}{lcc}
\hline Number & $\begin{array}{c}\text { Number of passengers } \\
\text { dispatched }\end{array}$ & Departure time \\
\hline 59 & 1100 & $20: 50$ \\
60 & 1100 & $21: 22$ \\
61 & 1100 & $21: 33$ \\
62 & 1100 & $21: 58$ \\
\hline
\end{tabular}

results. It should be noted, however, that the constructed model cannot accurately simulate passengers' free selection behaviors in different functional modules; thus the simulation results will have some differences to the real situations. Also, the simulation model's easy use has been weakened due to the fussy combination of different functional modules. A further improving of the simulation model may focus on adding the random selection characteristics of passengers at railway passenger station.

\section{Conclusions}

This paper proposes an evaluation model for the LOSWR based on the maximum number of passengers in waiting room of railway passenger station. A simulation model is then presented based on the Arena software to explore the influential factors on the LOSWR, as well as the effect utilities and priority of different measures on improving the LOSWR. The simulation results show that the passenger advanced arrival time has a significant effect on the maximum number of passengers and the LOSWR, and the accompany rate's effect is much weaker. For the measures that can be used to improve the LOSWR, the advanced check-out time has the strongest effect utility on improving the LOSWR, check-out speed, and the area of waiting room's effect utilities decrease in order. Therefore, the provided conclusions could be considered for operators' real-timely improving the LOSWR.

The results obtained in this study allow us to affirm that simulation method is a valuable and effective tool to understand the passengers' aggregation behaviors in waiting room. It is helpful to better formulate the station's organization plans and improve the LOSWR and other service units for operators. However, our work still has some limits. We assume the passenger advanced arrival time obeys the lognormal distribution; more practical fitting distribution functions that derive from field surveys are needed to make the results more accurate. Also, the passengers' free selection behaviors cannot reflect in the constructed simulation model. In future work, continuous efforts are needed to improve the simulation model which allows passengers' free selection behaviors. It will also be beneficial to explore more useful indicators such as passengers' average waiting time that can be used to evaluate the LOSWR comprehensively.

\section{Appendix}

\section{Number of Passengers Dispatched and Departure Time}

See Table 13. 


\section{Conflict of Interests}

The authors declare that there is no conflict of interests regarding the publication of this paper.

\section{Acknowledgments}

This work is financially supported by Chinese National 973 Project (2012CB725403) and the State Key Laboratory of Rail Traffic Control and Safety (RCS2014ZT15).

\section{References}

[1] S. P. Blainey and J. M. Preston, "A GIS-based appraisal framework for new local railway stations and services," Transport Policy, vol. 25, pp. 41-51, 2013.

[2] D. E. Reusser, P. Loukopoulos, M. Stauffacher, and R. W. Scholz, "Classifying railway stations for sustainable transitionsbalancing node and place functions," Journal of Transport Geography, vol. 16, no. 3, pp. 191-202, 2008.

[3] M. Givoni and P. Rietveld, "The access journey to the railway station and its role in passengers' satisfaction with rail travel," Transport Policy, vol. 14, no. 5, pp. 357-365, 2007.

[4] N. Karasmaa, "Evaluation of transfer methods for spatial travel demand models," Transportation Research Part A: Policy and Practice, vol. 41, no. 5, pp. 411-427, 2007.

[5] E. Nathanail, "Measuring the quality of service for passengers on the hellenic railways," Transportation Research Part A: Policy and Practice, vol. 42, no. 1, pp. 48-66, 2008.

[6] M. Brons, M. Givoni, and P. Rietveld, "Access to railway stations and its potential in increasing rail use," Transportation Research Part A: Policy and Practice, vol. 43, no. 2, pp. 136-149, 2009.

[7] J. Liu, "The service level evaluation of passenger railway station based on neural network approach," Railway Transport and Economy, vol. 30, no. 2, pp. 21-24, 2007.

[8] L. Eboli and G. Mazzulla, "Structural equation modelling for analysing passengers' perceptions about railway services," Procedia-Social and Behavioral Sciences, vol. 54, pp. 96-106, 2012.

[9] J. L. Wu and Y. Ma, "General railway passenger service level evaluation based on unascertained measurement theory," Shijiazhuang Tiedao University (Natural Science), vol. 24, no. 3, pp. 75-78, 2011.

[10] J.-T. Li and J. Fu, "Microscopic simulation model and analysis on waiting area of large scale railway passenger station," Journal of Transportation Systems Engineering and Information Technology, vol. 11, no. 1, pp. 44-49, 2011.

[11] J. J. Fruin, Pedestrian and Planning Design, Metropolitan Association of Urban Designers and Environmental Planners, New York, NY, USA, 1971.

[12] T.-W. Zhang, "Research on the assembling rule of passengers at railway passenger stations," Journal of the China Railway Society, vol. 31, no. 1, pp. 31-34, 2009.

[13] L. A. Bowman and M. A. Turnquist, "Service frequency, schedule reliability and passenger wait times at transit stops," Transportation Research Part A: General, vol. 15, no. 6, pp. 465471, 1981.

[14] E. Cascetta and F. Pagliara, "Integrated railways-based policies: the Regional Metro System (RMS) project of Naples and Campania," Transport Policy, vol. 15, no. 2, pp. 81-93, 2008.
[15] L. Li, The study of adaptability of service facilities and level of passenger railway station [Ph.D. thesis], Southwest Jiaotong University, Chengdu, China, 2007.

[16] M. W. Hu and Q. X. Shi, "Comparative study of pedestrian simulation model and related software," Transportation Information and Security, vol. 4, no. 27, pp. 122-127, 2009.

[17] Y.-Q. He, B.-H. Mao, S.-K. Chen, and J.-Y. Guo, "Research on the methods of calculating the maximum assembling at railway passenger stations," Journal of the China Railway Society, vol. 28, no. 1, pp. 6-11, 2006.

[18] T.-W. Zhang, M.-S. Wang, and X.-L. Wang, "Research on the forecast model of maximum assembling passengers at railway passenger stations in designing time," Journal of the China Railway Society, vol. 30, no. 5, pp. 105-108, 2008.

[19] Y.-Q. He, B.-H. Mao, Y. Ding, H.-Z. Zhang, and J. Yang, "Research on simulation calculation of maximum assembling of railway passenger station," System Simulation, vol. 18, no. 1, pp. 213-216, 2006.

[20] L. Yin and K. Zhu, "Modeling and simulation system of passenger terminal based on arena," Journal of Wuhan University of Technology (Transportation Science \& Engineering), vol. 33, no. 6, pp. 1199-1202, 2009.

[21] W. D. Kelton, R. P. Sadowski, and D. T. Sturrock, Simulation with Arena, McGraw-Hill, Singapore, 4th edition, 2007.

[22] J. L. Yao, Z. W. Wu, and Z. X. Yang, "The influence of urban traffic reliability to railway passenger station maximum assembling passengers," Railway Science and Engineering, vol. 6 , no. 5, pp. 84-88, 2009. 


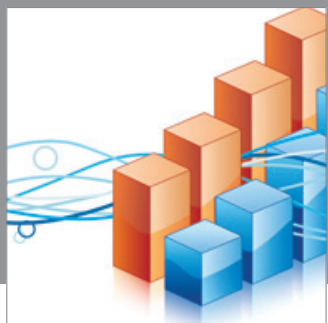

Advances in

Operations Research

mansans

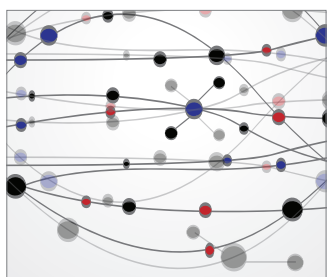

The Scientific World Journal
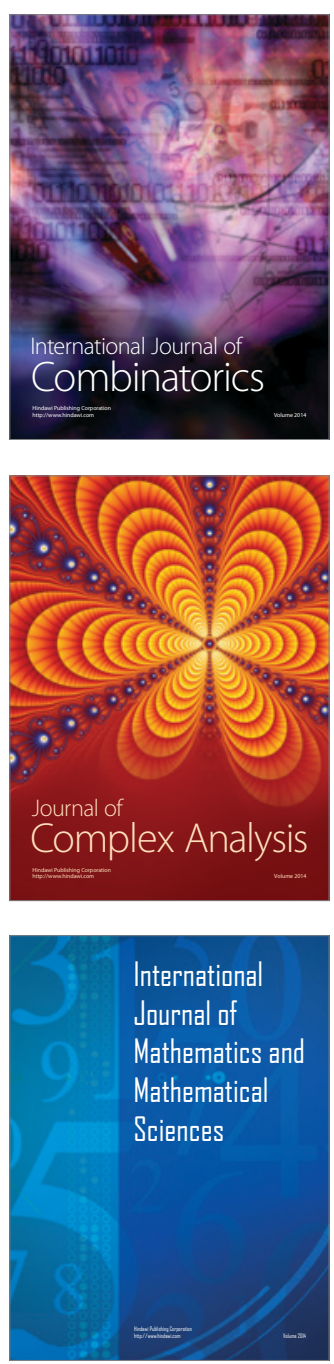
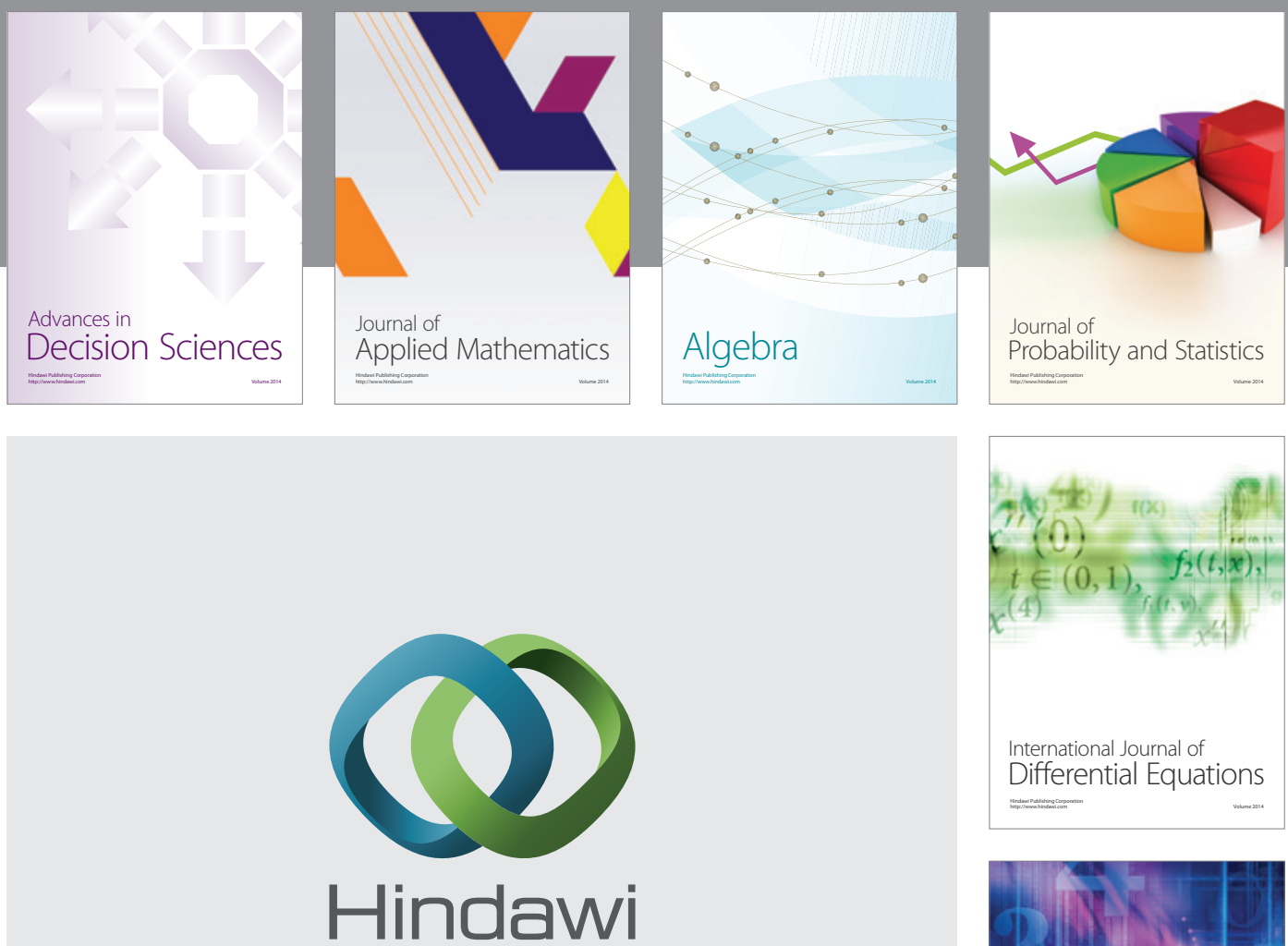

Submit your manuscripts at http://www.hindawi.com
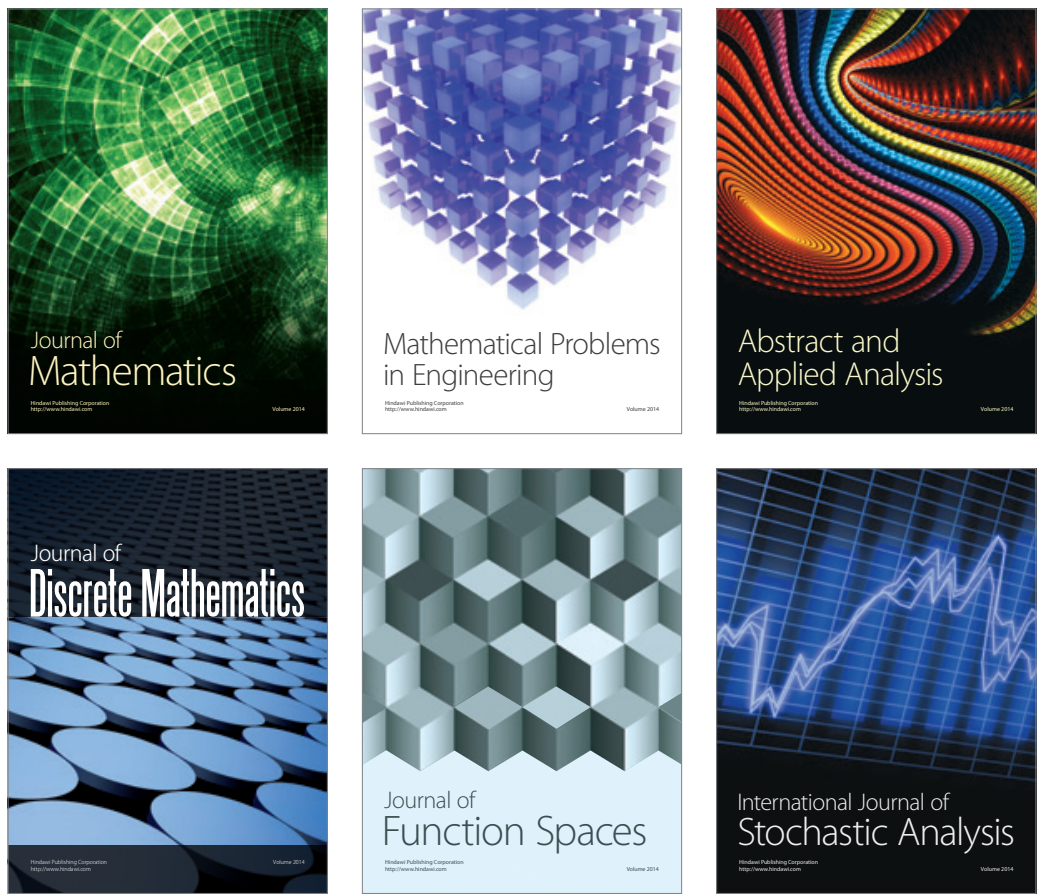

Journal of

Function Spaces

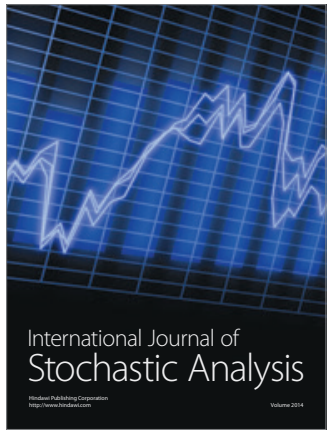

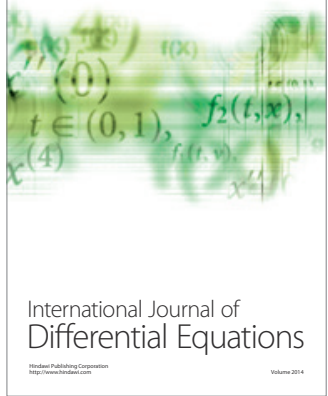
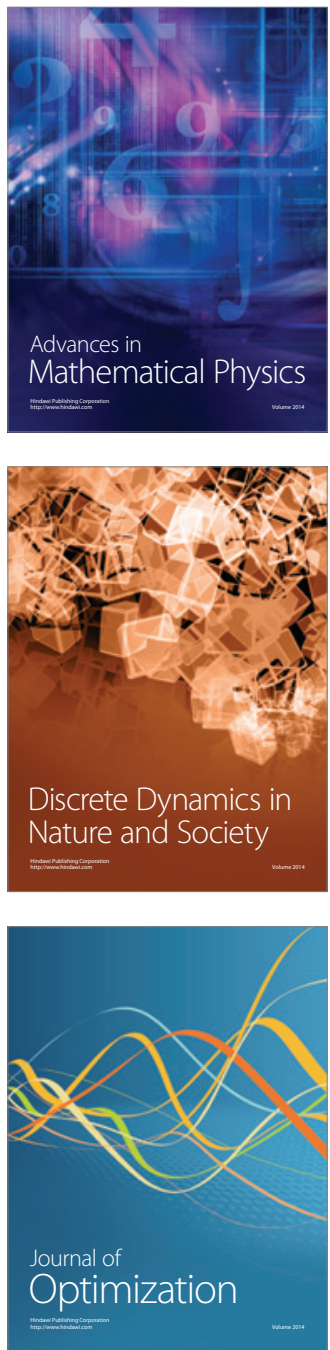